\title{
Evaluation of Some Etiological Factors of Haemolytic Disease of the New Born in Ile-Ife
}

\author{
Johnson Kayode Fadairo', Seto Tunrayo Aladenika1* ${ }^{*}$, Clement Osaiyuwu ${ }^{2}$, \\ Mathew F. Olaniyan', Kevin Aghatise ${ }^{2}$ \\ ${ }^{1}$ Achievers University, Owo, Nigeria \\ ${ }^{2}$ Igbinedion University, Okada, Nigeria \\ Email: ${ }^{*}$ setoalade@yahoo.com
}

Received 9 October 2013; revised 10 November 2013; accepted 20 November 2013

Copyright (C) 2014 by authors and Scientific Research Publishing Inc.

This work is licensed under the Creative Commons Attribution International License (CC BY). http://creativecommons.org/licenses/by/4.0/

(c) (i) Open Access

\begin{abstract}
Heamolytic disease of the newborn is a neonatal disease associated with red cells heamolysis resulting from red cell antigens of the foetus and mother red cells antibodies. This study involved a cross sectional laboratory based analytical survey, eighty neonates with pyrexia of unknown origin and twenty neonates apparently healthy were selectected for this study. ABO and Rh blood group, Direct Coombs' test, Glucose-6-phosphate dehydrogenase estimation and blood culture were performed on blood samples collected from each neonate. Blood group 0 had the highest number of neonates ( $60 \%$ control; $61 \%$ test); $80 \%$ and $81.3 \%$ of the control and test neonates are Rh positive respectively. None of the control subjects are positive to DCT while $5 \%$ of test subjects positive to DCT; $4 \%$ and $8.7 \%$ of the control and test respectively are positive to G6-PD deficiency. The study recorded $0 \%$ growth in blood culture of control subjects while $2.5 \%$ of the neonates blood samples yielded when cultured. Though prevalence rate of HDN in our society is diminishing gradually based on this study, there is need to look inwardly to other aetiological factors that can cause HDN apart from blood group incompatibility, since sudden infant death is on increase now.
\end{abstract}

\section{Keywords}

HDN; G6-PD; DCT; Red Cell

\section{Introduction}

Haemolytic disease of the newborn (HDN), erythroblastosis fetalis, is associated with foetal red cell destruction

*Corresponding author.

How to cite this paper: Fadairo, J.K., Aladenika, S.T., Osaiyuwu, C., Olaniyan, M.F. and Aghatise, K. (2014) Evaluation of Some Etiological Factors of Haemolytic Disease of the New Born in Ile-Ife. Open Journal of Clinical Diagnostics, 4, 5-11. http://dx.doi.org/10.4236/ojcd.2014.41002 
following the transplacental passage of maternally derived antigens on foetal cells. The IgG antibodies bind to foetal red cells, and in turn, these are destroyed following adherence to Fc receptors on macrophages in the spleen, by phagocytosis and extra cellular lysis. Haemolytic disease of the newborn can also result from incompatibilities caused by many other red cell antibodies, although this occurrence is much less frequent [1].

The incidence of immunization to red cells is related to the volume of red cell exposure. The Rh blood group antigen $\mathrm{D}$ is the most important cause of a family of inherited antigens. The theory of inheritance put forward by Fisher and Race states that there are three pairs of antigen, Dd, Cc and Ee. The presence of Rh (D) indicates Rh positivity while the absence of Rh (D) indicates Rh negativity.

Numerous advances have been made in the diagnosis and management of HDN and these have greatly decreased infant morbidity and mortality. The most significant development has been made in disease prevention. Although there is no cure for HDN, a method of antibody immunosuppression was developed to prevent Rh immunization which is an Rh-immunization mother [2].

This study was aimed at evaluation of some etiological factors of haemolytic disease of the new born, and its significance serological diagnosis, such as Glucose 6-phosphate dehydrogenase(G6PD), ABO and Rhesus blood group, and bacterial Infection. This study examined pattern and prevalence of ABO Blood Group and Rhesus Incompatibility among Neonates in, the distribution of G6PD deficiency among neonates sub infected of HDN in Ile-Ife and and bacteraemia in HDN.

\section{Materials and Methods}

Study Design A cross sectional Laboratory based analytical survey was adopted for this research.

\section{Study Area}

This study was carried out in Ile-Ife, Osun State, Nigeria. The Hospital used was Obafemi Awolowo University Teaching Hospital, Ile-Ife, Osun State Nigeria.

\section{Subjects}

The sample population consists of one hundred (100) neonates born at Obafemi Awolowo University Teaching Hospital, Ile-Ife, Osun State Nigeria. Eighty (80) of the neonates were diagnosed of pyrexia of unknown origin (PUO) while the other twenty (20) were aparently healthy. Ethical approval and subjects parents consent were obtained.

\section{Selection and Exclusion}

Both males and females were included in this study and all subjects were neonates between the age of 2 to 10 days. Neonates with history of complicated pregnacy, mother with history of malaria in pregnancy, Human Immunodeficiency (HIV) infection as well as alcoholism were excluded from this study.

\section{Collection of Samples}

$10 \mathrm{ml}$ of blood were collected from each neonates and about $2.5 \mathrm{ml}$ were dispensed into each blood culture bottle for culture. The medial cubital vein using a vacutainer and needle from each of the subjects into an Ethylene Diamine tetra acetic acid (EDTA) container.

\section{Study Duration}

Sample collection was from $6^{\text {th }}$ of January 2009 to $20^{\text {th }}$ of December 2010.

\section{Data Collection/Statistical Analysis}

Data was collected using self administered semi structure questionnaire. All numerical results were collated from the two groups. Data is presented as mean \pm Standard Deviation (S.D) and analyzed using one way analysis of variance (ANOVA).Using SPSS version 18.0. $\mathrm{P}$ values $\leq 0.05$ were considered significant.

ABO grouping 


\subsection{ABO and Rh Blood Groups Tests}

A drop of blood from each student was placed on a clean white tile in three places. A drop of each of the antisera, anti A, anti B and anti D was added and mixed with each blood sample, with the aid of glass rods. Blood was mixed thoroughly with the antisera and rocked gently for $60 \mathrm{sec}$ to observe agglutination. In case of doubt, the test was examined under a microscope, or the results were confirmed by reverse grouping using known group A and B red cells [3].

Direct Coombs’ Test (DCT): This was done according to Cheesbrough 2006 [4] using the neonates blood.

\subsection{Methaemoglobin Reduction Method for G6PD Estimation}

\section{Procedure:}

1) $2 \mathrm{ml}$ of anticoagulated blood (EDTA) was added to a tube containing $0.2 \mathrm{ml}$ of combined reagent (Dextrose, Sodium Nitrite, and Methylene blue).

2) The tube was closed with a stopper and the contents were gently mixed by inverting it 15 times.

3) Control tubes were prepared by adding $2 \mathrm{ml}$ of blood to a similar tube without reagents (Normal reference tube) and to a tube containing $0.1 \mathrm{ml}$ of sodium nitrite-dextrose mixture without methylene blue (deficient reference tube).

4) The samples were incubated at $37^{\circ} \mathrm{C}$ for 90 minutes.

5) After the incubation, add $0.1 \mathrm{ml}$ volume of the neonate sample, the normal reference tube and the deficient reference tube into $10 \mathrm{ml}$ of water in separate, clear glass test tubes of identical diameter.

6) The content were mixed gently and the colour of the different tubes were compared.

\subsection{Interpretation}

Normal blood yields a colour similar to that in the reference tube, a clear red.

Blood from defiant neonates give a brown colour similar to that in the deficient reference tube.

\section{Blood Culture}

The whole blood of the neonates is cultured using blood culture media.

Media used-Tryptone soya diphanic medium and Thioglycolate broth.

1) With the aid of a syringe and needle, about $10 \mathrm{ml}$ of blood B withdrawn from the neonates body.

2) The needle is inserted through the rubber liner of the bottle cap and the $5 \mathrm{ml}$ of blood is dispensed into each culture bottle (mentioned above).

3) The culture bottles are then incubated at $35^{\circ} \mathrm{C}-37^{\circ} \mathrm{C}$ up to 2 weeks, they are then examined and sub cultured on culture plates (this is prepared by adding $3 \mathrm{ml}$ of blood $1015-20 \mathrm{ml}$ of molten nutrients agar, mixing, and pouring into a Petri dish. The plate is incubated at $35^{\circ} \mathrm{C}-37^{\circ} \mathrm{C}$ over night.

4) The place is examined the following morning for possible growth.

\section{Results}

Both test and control samples were randomly analyzed for G6PD, DCT, ABO blood group, blood culture was also carried out on all samples.

The result for test and control samples is shown on the tables below.

From Table 1, it can be seen that for the two groups' majority of the patients were in Group blood $\mathrm{O}$ with 60 percent control and 61.3 percent for test. The group with least number of patient is blood group AB with $5 \%$ and 2.5\% respectively for control and test. One-quarter of control patients were in blood Groups A with close to onefifth of patients under test group; while for Group B it is 10 percent to 17.5 percent for Control and Test.

There exists no significant association between Blood Group and the Group the patients belong to i.e. (control and Test) the chi-square p-value is 0.750 .

Table 2 reveals that three-quarter of the patients had Rhesus (D) positive to One-quarter Rhesus (D) Negative for the patients under control group. For test on the other hand, it is $81.3 \%$ to $18.7 \%$ for Rhesus (D) positive and Rhesus (D) Negative respectively. Likewise, on the question of association, p-value is 0.899, meaning that there exist no significant association between Rhesus $\mathrm{D}$ and the group the patients belong. 
Table 1. Percentage distribution of ABO PHENOTYPE by group i.e. control and neonates.

\begin{tabular}{ccccc}
\hline \multirow{2}{*}{ Blood Group } & \multicolumn{2}{c}{ Apparently healthy neonates (Control) } & \multicolumn{2}{c}{ Neonates with PUO (Test) } \\
\cline { 2 - 5 } & No & $\%$ & No & $\%$ \\
\hline Group O & 12 & 60.0 & 49 & 61.3 \\
A & 5 & 25.0 & 15 & 18.7 \\
B & 2 & 10.0 & 4 & 17.5 \\
AB & 1 & 5.0 & 2 & 2.5 \\
Total & 20 & 100.0 & 80 & 100.0 \\
\hline
\end{tabular}

Table 2. Percentage distribution of Rhesus (D) PHENOTYPE by control and neonates.

\begin{tabular}{ccccc}
\hline & \multicolumn{2}{c}{ Apparently healthy neonates (Control) } & \multicolumn{2}{c}{ Neonates with PUO (Test) } \\
\cline { 2 - 5 } Rhesus (D) & No & $\%$ & No & $\%$ \\
\hline Rhesus (D) Positive & 16 & 80.0 & 65 & 1.3 \\
Rhesus (D) Negative & 4 & 20.0 & 15 & 18.7 \\
Total & 20 & 100.0 & 80 & 100.0 \\
\hline
\end{tabular}

From Table 3, none of the patient under control have positive (DCT). All the patients had Negative (DCT) while for test $5.0 \%$ of the patients had positive (DCT) to $95.0 \%$ that had Negative (DCT). On whether there is any significant association between the group they belong to DCT, the computer revealed that there is no significant association between the group and DCT with p-value of (0.307) which is more than the 0.05 significant level required.

From Table 4, 80\% of control patients had No deficient while 20\% had deficient in their G6PD. For test, it is $91.3 \%$ to $8.7 \%$ for Not deficient and Deficient respectively. Also on the question of association, there exist no significant association since our p-value (0.50) is greater than 0.05 .

From Table 5, the percentage distribution reveals that all the patients had no growth in their blood culture. For test it is $2.5 \%$ to $97.5 \%$ for growth and No Growth respectively. On the question of whether there is association the p-value of the Pearson chi-square is 0.475 which is greater than 0.05 , it then means that there is no significant association between the group they belong and their blood culture.

From Table 1, it can be seen that for the two groups' majority of the patients were in Group blood O with 60 percent control and 61.3 percent for test. The group with least number of patient is blood group $\mathrm{AB}$ with $5 \%$ and $2.5 \%$ respectively for control and test. One-quarter of control patients were in blood Groups A with close to one-fifth of patients under test group; while for Group B it is 10 percent to 17.5 percent for Control and Test.

There exists no significant association between Blood Group and the Group the patients belong to i.e. (control and Test) the chi-square p-value is 0.750 .

Table 2 reveals that three-quarter of the Neonates had Rhesus (D) positive to One-quarter Rhesus (D) Negative for the Neonates under control group. For test on the other hand, it is $81.3 \%$ to $18.7 \%$ for Rhesus (D) positive and Rhesus (D) Negative respectively. Likewise, on the question of association, p-value is 0.899, meaning that there exist no significant association between Rhesus $\mathrm{D}$ and the group the patients belong.

From Table 3, none of the Neonates under control have positive (DCT). All the Neonates had Negative (DCT) while for test $5.0 \%$ of the Neonates had positive (DCT) to $95.0 \%$ that had Negative (DCT). On whether there is any significant association between the group they belong to DCT, the computer revealed that there is no significant association between the group and DCT with p-value of (0.307) which is more than the 0.05 significant level required.

From Table 4, 80\% of control Neonates had No deficient while 20\% had deficient in their G6PD. For test, it is $91.3 \%$ to $8.7 \%$ for Not deficient and Deficient respectively.

Also on the question of association, there exist no significant association since our p-value (0.50) is greater than 0.05 . 
Table 3. Percentage distribution of DCT by control and neonates.

\begin{tabular}{ccccc}
\hline \multirow{2}{*}{ DCT } & \multicolumn{2}{c}{ Apparently healthy neonates(Control) } & \multicolumn{2}{c}{ Neonates with PUO (Test) } \\
\cline { 2 - 5 } & No & $\%$ & No & \% \\
\hline Positive (+) & - & - & 76 & 5.0 \\
Negative (-) & 20 & 100.0 & 80 & 100.0 \\
Total & 20 & 100.0 & 80 \\
\hline
\end{tabular}

Table 4. Percentage distribution of G6PD by group. i.e. control and neonates.

\begin{tabular}{ccccc}
\hline \multirow{2}{*}{ G6PD } & \multicolumn{2}{c}{ Apparently healthy neonates (Control) } & \multicolumn{2}{c}{ Neonates with PUO (Test) } \\
\cline { 2 - 5 } & No & $\%$ & No & \% \\
\hline Not Deficient & 16 & 80.0 & 73 & 7.3 \\
Deficient & 4 & 20.0 & 7 & 8.7 \\
Total & 20 & 100.0 & 80 & 100.0 \\
\hline
\end{tabular}

Table 5. Percentage distribution of blood culture by control and neonates.

\begin{tabular}{ccccc}
\hline \multirow{2}{*}{ Blood Culture } & \multicolumn{2}{c}{ Apparently healthy neonates (Control) } & \multicolumn{2}{c}{ Neonates with PUO (Test) } \\
\cline { 2 - 5 } & No & $\%$ & No & 2.5 \\
Growth & - & - & 2 & 97.5 \\
No Growth & 20 & 100.0 & 78 & 100.0 \\
Total & 20 & 100.0 & 80 & \\
\hline
\end{tabular}

From Table 5, the percentage distribution reveals that all the Neonates had no growth in their blood culture. For test it is $2.5 \%$ to $97.5 \%$ for growth and no growth respectively. On the question of whether there is association the p-value of the Pearson chi-square is 0.475 which is greater than 0.05 , it then means that there is no significant association between the group they belong and their blood culture.

\section{Discussion and Conclusion}

Haemolytic Disease of the New born, also known as erythroblastosis fetalis, is a neonatal disease characterized by the destruction of the red blood cells of the affected neonates [5]. Its major etiological factor is the absence of positive direct comb's test, and other pathological jaundice may be interest which includes intrauterine congenital infections, erythrocyte membrane defect, red blood cell enzyme deficiencies and no hemolytic causes, such as enclosed hemorrhages, hypothyroidism, gastrointestinal obstruction and metabolic diseases [6].

The focus of this work is to review the etiological factors involved in Haemolytic Disease of the New born and the significance of the Serological diagnosis. The factors are the ABO \& rhesus blood group, G6PD deficiencies and the isolation of possible bacteria [blood Culture). A total of 100 samples were collected, 20 samples were used as controls (apparently healthy neonate) while 80 samples were collected from neonates with history of pyrexia. Control and test subject under the blood group O have the highest frquency (60\%), though slightly higher than their findings; blood group $\mathrm{O}$ had been reported in previuos research to be blood group with highest frequency in Nigeria [7]-[12]. There had not been any difference in blood group distribution of adult and neonate since blood group is a phenotype which can not change. $80 \%$ of the control neonates are rhesus positive while test subjects are $81 \%$ rhesus positive. This was in line with report of Akinnuga et al. [8]. The Rh blood group system is the most polymorphic of the human blood groups, consisting of at least 45 independent antigens and next to the ABO system is the most clinically significant in transfusion medicine [13]. In the Caucasians in the United States, the distribution is type O, 47\%, type A, 41\%; type B, $9 \%$ and type AB; $3 \%$ and for the blacks in the United States, the distribution is type O, 46\%; type A, 27\%; type B, $2 \%$ and AB, $7 \%$ [14]. Both rhesus 
factors and ABO blood group had been noted to be the major aetiological factor in erythroblastosis fetalis [15]. However, HDN is three times more likely to be caused by ABO incompatibility than Rhesus incompatibility due to the low number of Rh negative women in African and Asian populations [4].

Only five percent (5\%) of our test subjects were positive to Direct comb's test (DCT); hence all control subjects were negative to this test. This can be explained as a situation due to the fact that there had not been any previous sensitization of these neonates red cells or their red cells had not been coated with antibidy. Direct coomb's test also known as direct antiglobulin test had been reported to be positive in neonates with HDN. Though Heddle et al. reported three cases of negative DCT in Rh haemolytic anaemia in neaonate [16], in this such were not found.

4(20\%) control and 7(8.7\%) test neonates are positive G-6-PD deficient in this study. G-6-PD deficiency had been reported to be the most common enzymopathy in humans [17], it functions in maintenance of red blood cells membrane stability [18]. Glucose-6-phosphate dehydrogenase (G-6-PD), deficiency leads to impaired production of reduced glutathione and predisposes the red cells to be damaged by oxidative metabolites, causing hemolysis [19] this end result also mimic that found in HDN. Though heamolysis of neonates red blood cells may be also due to enzym deficiency but blood group incompability is what is generally referred to as HDN. In this study prevalency of G6PD deficiency in control subjects is same with previous research work on G-6-PD in Nigeria [20], however this value is higher compared with our test subjects.

In this study $2.5 \%$ of test subject had bactereamia, none of the control subject positive to bactereamia; hence it was contrary to earlier reports [21]-[23]. Though in this study emphasis was not placed on species of bacteria present, Klebsiella pneumonia had been reported to be the organism with highest occurance [24]-[26]. In this study pyrexia had been used as a selecting criterion for neonate under test subjects; hence the association of neonatal bacteria septiceamia with hemolysis had been thoroughly studied [27], but non had reported the association with HDN. In certain studies, infections had been reported to be one of the major factors that elicit the heamolysis in G-6-PD [19] [28]; hence its role in HDN is poorly understood. The low incidence of neonatal bacteria septiceamia might be attributed to increased hygenic condition given to neonate. In vitro, bacteria contamination of blood had been seen to cause transfusion reaction; hence there is a possibility for bacterial septiceamia in neonates resulting in a reaction similar to HDN.

In conclusion, the incidence of Haemolytic disease of the New born (HDN) in Ile-Ife using the Direct comb's test as a diagnostic technique to detect the presence of sensitized red blood cell of the neonate shows no significance. This might due to the level of awareness of the disease among expecting mothers before and during pregnancy; this enables them to take necessary precautions and management from the investigation carried out, the infection in HDN is at minimal and the deficiency of G6PD is not common. Though prevalence rate of HDN in our society is diminishing gradually, there is need to look inwardly to other aetiological factors that can cause HDN apart from blood group incompatibility, since sudden infant death is on increase now.

\section{References}

[1] Van Dijk, B.A., Hirasing, R.A. and Overbeeke, M.A. (1999) Hemolytic Disease of the Newborn and Irregular Blood Group Antibodies in the Netherlands: Prevalence and Morbidity. Ned Tijdschr Geneeskd, 143, 1465-1469.

[2] Chavez, G.F., Mulinare, J. and Edmonds, L.D. (1991) Epidemiology of Rh Hemolytic Disease of the Newborn in the United States. The Journal of the American Medical Association, 265, 3270-3274. http://dx.doi.org/10.1001/jama.1991.03460240066029

[3] Dacie, J.V. and Lewis, S.M. (2001) Practical Haematology. In: Lewis, S.M., Bain, B.J. and Bates, I. Eds., Practical Heamatology, 9th Edition, Churchill Livingstone, Harcourt Publishers Limited, London, 444-451.

[4] Cheesbrough, M. (2000) Direct Combs’ Test. In: District Laboratory Practice in Tropical Countries, Part 2. 2nd Editon, Cambridge University Press, New York, 221-245.

[5] Thakral, B., Malhotra, S., Saluja, K., Kumar, P. and Marwaha, N. (2010) Hemolytic Disease of Newborn Due to Anti-Jkb in a Woman with High Risk Pregnancy. Transfusion and Apheresis Science, 43, 41-43. http://dx.doi.org/10.1016/j.transci.2010.05.007

[6] Luchtman-Jones, L., Schwartz, A.L. and Wilson, D.B. (1997) The Blood and Hematopoietic System. In: Fanaroff, A.A. and Martin, R.J., Eds., Neonatal-Perinatal Medicine-Diseases of the Fetus and Infant, 6th Edition, Mosby, St. Louis, 1201-1287.

[7] Olaniyan, T.O., Ajibola, B.M., Rasong, H., Dare, B.J. and Shafe, M.O. (2013) Blood Group and Rhesus Factor Pattern among Indigenes of FCT, Abuja, Nigeria. Journal of Community Medicine \& Health Education, 3, 208. 
http://dx.doi.org/10.4172/2161-0711.1000208

[8] Akinnuga, A.M., Bamidele, O., Amosu, A.M. and Ugwah, G.U. ( 2011) Distribution of ABO and Rh Blood Groups among Major Ethnic Groups of Medical Students of Madonna University Teaching Hospital, Elele, Nigeria. Asian Journal of Medical Sciences, 3, 106-109.

[9] Adeyemo, O.A. and Soboyejo, O.B. (2006) Frequency Distribution of ABO, RH Blood Groups and Blood Genotypes among the Cell Biology and Genetics Students of University of Lagos, Nigeria. African Journal of Biotechnology, 5, 2062-2065.

[10] Nwauche, C.A. and Ejele, O.A. (2004) ABO and Rhesus Antigens in a Cosmopolitan Nigeria Population. Nigerian Journal of Medicine, 13, 263-266.

[11] Kulkarni, A.G., Peter, B., Ibazebo, R., Dash, B. and Fleming, A.F. (1985) The ABO and Rhesus Groups in the North of Nigeria. Annals of Tropical Medicine and Parasitology, 79, 83-88.

[12] Falusi, A.G., Ademowo, O.G., Latunji, C.A., Okeke, A.C., Olatunji, P.O., Onyekwere, T.O., Jimmy, E.O., Raji, Y., Hedo, C.C., Otukonyong E.E. and Itata, E.O. (2000) Distribution of ABO and RH Genes in Nigeria. African Journal of Medicine and Medical Sciences, 29, 23-26.

[13] Avent, N.D. and Reid M.E. (2000) The Rh Blood Group System: A Review. Blood, 95, 375-387.

[14] Seeley, R.R., Stephens, T.D. and Tate, P. (1998) Anatomy and Physiology. 4th Edition, the McGraw Hill Companies, Inc., New York City, 1098.

[15] Dean, L. (2005) Blood Groups and Red Cell Antigens [Internet]. National Center for Biotechnology Information (US), Bethesda (MD), Chapter 4, Hemolytic Disease of the Newborn. http://www.ncbi.nlm.nih.gov/books/NBK2266/

[16] Heddle, N.M., Wentworth, P., Anderson, D.R., Emmerson, D., Kelton, J.G. and Blajchman, M.A. (1995) Three Examples of Rh Haemolytic Disease of the Newborn with a Negative Direct Antiglobulin Test. Transfusion Medicine, 5, 113-116. http://dx.doi.org/10.1111/j.1365-3148.1995.tb00197.x

[17] Mehta, A., Mason, P.J. and Vulliamy, T.J. (2000). Glucose-6-Phosphate Dehydrogenase Deficiency. Best Practice \& Research Clinical Haematology, 13, 21-38.

[18] Beutler, E. (1994) G6PDdeficiency. Blood, 84, 3613-3636.

[19] Manik, M., Asok, K.D, Syamali, M. and Pradip, K.D. (2012) Study of Glucose-6-Phosphate Dehydrogenase Deficiency in Neonatal Jaundice. Journal of Pharmacy and Biological Sciences, 1, 30-36.

[20] WHO (1997) Technical Report on Standardization of Procedures for the Study of G-6-PD.

[21] Asindi, A.A., Ibia, E.O. and Udo, J.J. (1991) Mortality Pattern among Nigerian Children in the 1980s. The Journal of Tropical Medicine and Hygiene, 94, 152-155.

[22] Komolafe, A.O. and Adegoke, A.A. (2008) Incidence of Bacterial Septicaemia in Ile-Ife Metropolis, Nigeria Malaysian Journal of Microbiology, 4, 51-61.

[23] Nwadioha, S.I., Nwokedi, E., Odimayo, M.S., Okwori, E.E. and Kashibu, E. (2010) Bacterial Isolates in Blood Cultures of Children with Suspected Septicaemia in a Nigerian Tertiary Hospital. The Internet Journal of Infectious Diseases, 8. http://dx.doi.org/10.5580/143

[24] West, B.A. and Peterside, O. (2012) Sensitivity Pattern among Bacterial Isolates in Neonatal Septicaemia in Port Harcourt. Annals of Clinical Microbiology and Antimicrobials, 11, 7. http://dx.doi.org/10.1186/1476-0711-11-7

[25] Desai, K.J. and Malek, S.S. (2010) Neonatal Septicemia: Bacterial Isolates \& Their Antibiotics Susceptibility Patterns. National Journal of Integrated Research in Medicine, 1, 12-15. http://njirm.pbworks.com/w/file/fetch/31225028/5neonetal septisemia.pdf

[26] Iregbu, K.C., Elegba, O.Y. and Babaniyi, I.B. (2006) Bacteriological Profile of Neonatal Septicaemia in a Tertiary Hospital in Nigeria. African Health Sciences, 6, 151.

[27] Onyearugha, C.N., Onyire, B.N. and Ugboma, H.A.A. (2011) Neonatal Jaundice: Prevalence and Associated Factors as Seen in Federal Medical Centre Abakaliki, Southeast Nigeria. Journal of Clinical Medicine and Research, 3, 40-45.

[28] Farhud, D.D. and Yazdanpanah, L. (2008) Glucose-6-Phosphate Dehydrogenase (G6PD) Deficiency Iranian. Journal of Public Health, 37, 1-18. 